\title{
Computational Study of Structure and Reactivity of Oligomeric Vanadia Clusters Supported on Anatase and Rutile $\mathrm{TiO}_{2}$ Surfaces
}

\author{
Hui $\mathrm{Fu}^{*}{ }^{\dagger}$ Zhiyao Duan, ${ }^{*}+$ and Graeme Henkelman ${ }^{\ddagger}$ \\ 'State Key Laboratory of Heavy Oil Processing, College of Science, China University of Petroleum, Qingdao, Shandong 266580, \\ People's Republic of China \\ ${ }^{\ddagger}$ Department of Chemistry and the Institute for Computational Engineering and Sciences, The University of Texas at Austin, Austin, \\ Texas 78712-0165, United States
}

\section{Supporting Information}

ABSTRACT: We use density functional theory to examine structureactivity relationships of small vanadia clusters supported on anatase $\mathrm{TiO}_{2}(001)$ and rutile $\mathrm{TiO}_{2}(110)$ surfaces. A thermodynamic analysis indicates that the vanadia monomer cluster can be stabilized on the anatase $\mathrm{TiO}_{2}(001)$ surface in a catalytically relevant oxygen environment. On the other hand, vanadia clusters tend to aggregate into dimers on the rutile $\mathrm{TiO}_{2}(110)$ surface because this surface binds the monomer less strongly as compared to anatase. Hydrogen adsorption is found to be exothermic on the vanadia monomer adsorbed on both supports, enhanced by a charge transfer between the adsorbate and the substrate. There is no such charge transfer on vanadia dimers and tetramers, where the hydrogen adsorption energies are similar to that on the single crystal $\mathrm{V}_{2} \mathrm{O}_{5}(001)$ surface. The improved catalytic performance of the anatase support can be attributed to the ability of this surface to stabilize the catalytically active vanadia monomer clusters.
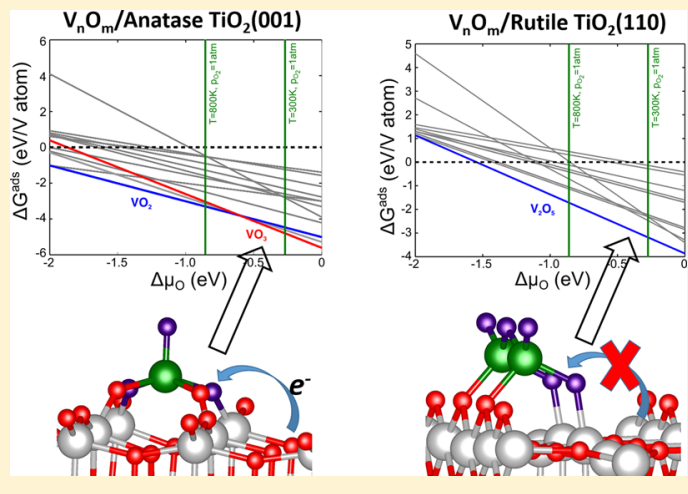

\section{INTRODUCTION}

The growing demand of olefins and aldehydes as raw materials in industry calls for catalysts that can produce them in an efficient and economical way. One promising way is the catalytic oxidative dehydrogenation (ODH) of light alkanes and alcohols to the corresponding alkenes and aldehydes. The advantages of $\mathrm{ODH}$ over conventional nonoxidative routes rely on the fact that the ODH reaction is (i) exothermic and can operate at low temperature and (ii) minimizes coke deposition which eventually deactivates the catalysts. Oxide-supported vanadium oxide catalysts $\left(\mathrm{VO}_{x}\right)$ have been demonstrated to exhibit high activity for the $\mathrm{ODH}$ reaction. ${ }^{1-3}$ However, the yield of desirable products is still limited by undesirable total combustion reactions. An increase in the activity and selectivity of this reaction would be aided by a fundamental understanding of the structure-activity relationship at the molecular level.

The structure-activity relationship of $\mathrm{VO}_{x}$ has long been pursued in experiments, ${ }^{4-8}$ where different structures of $\mathrm{VO}_{x}$ are prepared by varying the vanadium loading on a given support. With increasing vanadium loading, $\mathrm{VO}_{x}$ catalysts are proposed to change in structure from monomers, oligomers, monolayers, to $3 \mathrm{D}$ crystalline $\mathrm{V}_{2} \mathrm{O}_{5}$ nanoparticles. The structure of $\mathrm{VO}_{x}$ clusters at different coverages and their corresponding performance are characterized and measured to establish structure-activity relationships. For the $\mathrm{TiO}_{2}$ support, which is of interest in this study, it is believed that the turnover frequency (TOF) at the $\mathrm{VO}_{x} / \mathrm{TiO}_{2}$ catalyst is relatively insensitive to coverage, whereas $\mathrm{V}_{2} \mathrm{O}_{5}$ nanoclusters with a size of 1-2 nm exhibit high $\mathrm{ODH}$ activity. At higher coverages, the activity drops when extensive crystalline $\mathrm{V}_{2} \mathrm{O}_{5}$ forms.

Although these studies provide valuable insight, a structureactivity relationship with molecular resolution should be pursued since the currently employed characterization methods do not provide unambiguous structural information at the atomic scale. Density functional theory (DFT) is a valuable tool that is complementary to experiments because the electronic structure and chemical properties can be calculated for a welldefined atomic structure. Hence, the proposed structures from experimental characterization can be screened using DFT calculations. A successful example of such an experimentaltheoretical collaboration is the resolution of the structure of $\mathrm{VO}_{x} / \mathrm{CeO}_{2}$ which has been understood using a combination of high-resolution scanning tunneling microscopy (STM) and DFT. ${ }^{9}$ In a later contribution, temperature-programmed desorption (TPD) confirmed that $\mathrm{VO}_{x} / \mathrm{CeO}_{2}$ at low vanadia loadings catalyzes the methanol $\mathrm{ODH}$ reaction at a lower temperature than either pure ceria or vanadia. ${ }^{10}$ The origin of this promotion effect is explained using DFT calculations showing that the charge transfer from the reduced vanadia adsorbate to the localized $f$-states of the ceria support stabilizes the reduced state and accelerates the $\mathrm{H}$ abstraction process.

Received: March 13, 2015

Revised: June 4, 2015

Published: June 5, 2015 
Like ceria, $\mathrm{TiO}_{2}$ is one of the reducible supports that outperforms irreducible supports for a number of catalytic reactions. While much work has been devoted to resolving atomic-scale structures of the $\mathrm{VO}_{x} / \mathrm{TiO}_{2}$ catalyst both experimentally and theoretically, there is no consensus for the origin of the high TOF on this catalyst. On a rutile $\mathrm{TiO}_{2}$ support, the atomic structures of $\mathrm{V}_{1}, \mathrm{~V}_{2}, \mathrm{VO}$, and $\mathrm{VO}_{2}$ clusters have been investigated using STM and DFT. ${ }^{11}$ More recently, combining XPS (X-ray photoelectron spectroscopy), AR-PD (angle resolved photoelectron diffraction), and DFT calculations, $\mathrm{VO}_{x}$ nanoclusters supported on rutile $\mathrm{TiO}_{2}$ were found to have a strong tendency toward aggregating into polynuclear nanoclusters. ${ }^{12}$ The structure of these $\mathrm{VO}_{x}$ nanoclusters was proposed to be $\mathrm{V}_{4} \mathrm{O}_{6}$ aligned along the [001] direction of the $\mathrm{TiO}_{2}$ substrate. It is unexpected that vanadyl groups are present in $\mathrm{V}_{4} \mathrm{O}_{6}$ given the formal vanadium oxidation state of 3+. TPD experiments additionally show that $\mathrm{V}_{4} \mathrm{O}_{6}$ nanoclusters can selectively convert methanol to formaldehyde at temperatures as low as $300 \mathrm{~K}$. In another study, $\mathrm{V}^{5+}$ and $\mathrm{V}^{4+}$ ions were found to be the dominant species on rutile $\mathrm{TiO}_{2}$ supported sub-ML, ${ }^{13}$ $\mathrm{ML},{ }^{14}$ and $2 \mathrm{ML} \mathrm{VO}_{x}$ catalysts $^{15}$ in oxidizing and reducing environments, respectively. Structural changes of the $\mathrm{VO}_{x}$ catalysts were also observed in these studies during the reduction-oxidation (redox) reaction. DFT calculations have been conducted to elucidate the atomic structure of the vanadia monomer supported on rutile $\mathrm{TiO}_{2}{ }^{16}$ Conventionally, supported vanadia clusters are postulated to possess a tetrahedrally coordinated $\mathrm{VO}_{4}$ structure. Although this is true for some supports (e.g., $\mathrm{CeO}_{2}$ and $\mathrm{SiO}_{2}$ ), it is found not to be the case for rutile $\mathrm{TiO}_{2}$. The vanadia monomer that is calculated to be stable on rutile $\mathrm{TiO}_{2}$, under catalytic conditions, maintains an octahedrally coordinated oxygen environment, which is similar to that of a $\mathrm{V}$ atom in bulk $\mathrm{V}_{2} \mathrm{O}_{5}$.

In this paper, we employ DFT calculations to investigate the atomic and electronic structures, as well as the catalytic properties of small $\mathrm{VO}_{x}$ clusters (monomer, dimer, and tetramer) supported on rutile $\mathrm{TiO}_{2}(110)$ and anatase $\mathrm{TiO}_{2}(001)$ surfaces. It is found that the $\mathrm{VO}_{x}$ monomer has distinct catalytic properties compared to the dimer and tetramer due to a substrate to adsorbate electron transfer. Coupling DFT calculations with thermodynamic considerations, stable $\mathrm{VO}_{x}$ structures under realistic oxygen environments are obtained. It is demonstrated that rutile and anatase supports exhibit a different ability to disperse $\mathrm{VO}_{x}$ clusters. The strong support-adsorbate interaction on the anatase support stabilize both the vanadia monomer $\left(\mathrm{VO}_{3}\right)$ and dimer $\left(\mathrm{V}_{2} \mathrm{O}_{5}\right)$, containing $\mathrm{V}^{5+}$, whereas only the vanadia dimer $\left(\mathrm{V}_{2} \mathrm{O}_{5}\right)$ is stable on the rutile support. We propose that the different stable $\mathrm{VO}_{x}$ species may be the reason for the observed higher catalytic activity on the anatase substrate.

\section{COMPUTATIONAL METHODS}

Total energy calculations were performed using spin-polarized periodic DFT calculations with a plane-wave basis set as implemented in the Vienna $\mathrm{Ab}$ Initio Simulation Package (VASP). ${ }^{17-19}$ The PBE (Perdew-Burke-Ernzerhof) functional $^{20}$ form of the generalized gradient approximation was employed to calculated exchange-correlation energies. The projector augmented wave method $(\mathrm{PAW})^{21,22}$ was used to describe the electron-ion interaction. A kinetic energy cutoff of $400 \mathrm{eV}$ for the plane-wave basis set was used in the calculations. A Hubbard $U$ term was added to the PBE functional to penalize the artificial tendency for partial occupation of the electronic states of interest, which is caused by an incomplete cancellation of the Coulomb self-interaction. The Hubbard $U$ term employed follows the rotationally invariant formalism by Dudarev et al., ${ }^{23}$ in which only the difference $U_{\text {eff }}=U-J$ between the Coulomb $U$ and exchange $J$ parameters matter. A $U_{\text {eff }}$ of $4.0 \mathrm{eV}$ was applied to the $3 \mathrm{~d}$ states of $\mathrm{Ti}$ and $\mathrm{V}$. This value was chosen because it results in similar localized defect electronic states that have been experimentally observed. ${ }^{24-26}$

The $\mathrm{TiO}_{2}$ substrates were simulated with slab models consisting of four stoichiometric layers for both the anatase (001) and rutile (110) surfaces. A vacuum gap of $20 \AA$ was used to separate periodic images of the system imposed by the periodic boundary condition in the $z$ direction. Unit cells of ( 3 $\times 3)$ and $(4 \times 2)$ were employed for the anatase $(001)$ and rutile (110) surfaces, respectively. $\mathrm{V}_{n} \mathrm{O}_{m}(n=1,2,4$ and $m=$ 1-8) clusters were deposited on the $\mathrm{TiO}_{2}$ supports. Here, we adopt a convention that the $m$ oxygen atoms come from the environment in addition to the lattice oxygen of the stoichiometric $\mathrm{TiO}_{2}$ substrate. For each vanadia cluster, a number of possible structures were examined to obtain stable configurations. Convergence tests showed that while the size of the slab did affect the absolute binding energies of vanadia clusters (especially on anatase support because of large surface relaxation), the relative binding energies, which determine the physically relevant structures, are largely insensitive to the size of the unit cell. Due to the large surface model employed, the $\Gamma$ point was sufficient to sample the Brillouin zone. Structural optimization was considered converged when all components of the force fell below $0.05 \mathrm{eV} / \AA$. During the relaxation, the top two layers of the $\mathrm{TiO}_{2}$ support and the supported vanadia clusters were allowed to relax, while the bottom two layers were kept fixed to their bulk positions.

A Bader charge analysis ${ }^{27,28}$ was employed to determine the local charge of atoms in the system, defined by the integrated charge density within Bader volumes around the atoms. Magnetic moments were determined by calculating the integrated spin density within the Bader volumes.

Entropic contributions to the free energy were calculated at the harmonic level. Vibrational frequencies of the normal modes were obtained by diagonalization of the mass-weighted force constant matrix, obtained by finite difference. A central difference scheme, using a displacement of $0.015 \AA$ along the Cartesian directions for the supported $\mathrm{V}$ and $\mathrm{O}$ atoms, was used to evaluate the Hessian matrices.

Ab Initio Thermodynamics. As a starting point for studying the catalytic properties of $\mathrm{V}_{n} \mathrm{O}_{m}$ clusters, it is important to know which $\mathrm{V}_{n} \mathrm{O}_{m}$ clusters are the most stable under catalytically relevant conditions. To this end, the ab initio thermodynamics method ${ }^{29}$ was employed to examine the relative stability of various $\mathrm{V}_{n} \mathrm{O}_{m}$ clusters in an $\mathrm{O}_{2}$ environment by comparing their corresponding formation energy on $\mathrm{TiO}_{2}$ supports. The Gibbs free energy of formation of a $\mathrm{V}_{n} \mathrm{O}_{m}$ cluster is defined as

$$
\Delta G^{\mathrm{f}} \approx-\frac{1}{n} E_{\mathrm{V}_{n} O_{m}}^{\mathrm{f}}+\frac{m}{n} \Delta \mu_{\mathrm{O}}(T, p)
$$

where $E_{V n O m}^{f}$ (the formation energy of $\mathrm{V}_{n} \mathrm{O}_{m}$ ) is defined as

$$
E_{V_{n} O_{m}}^{\mathrm{f}}=E_{\mathrm{V}_{n} \mathrm{O}_{m} / T i O_{2}}^{\text {tot }}-E_{T_{i O_{2}}}^{\text {tot }}-n E_{V_{\mathrm{bcc}}}^{\text {tot }}-\frac{m}{2} E_{\mathrm{O}_{2}}^{\text {tot }}
$$

In eqs 1 and 2, an approximation enters by replacing the Gibbs free energy of the solid components with DFT total energies. Note that no Hubbard $U$ term is applied when calculating the 
total energy of the vanadium bulk. This approximation has been justified previously in that the $p V$ term and the vibrational contributions to the entropy can be neglected without changing the qualitative results of this kind of study. In addition, we have conducted calculations to obtain the vibrational enthalpy and entropy of supported $\mathrm{V}_{n} \mathrm{O}_{m}$ clusters and found the relative stability is only marginal changed by including these free energy contributions. In eq $1, \Delta \mu_{\mathrm{O}}(T, p)$ is the chemical potential of oxygen, which is determined at variable $(T, p)$ conditions as,

$$
\Delta \mu_{\mathrm{O}}(T, p)=\frac{1}{2}\left(\tilde{\mu}_{\mathrm{O}_{2}}\left(T, p^{0}\right)+k_{\mathrm{B}} T \ln \frac{p_{\mathrm{O}_{2}}}{p^{0}}\right)
$$

In the above equation, $p^{0}$ is the standard pressure, and $\tilde{\mu}_{\mathrm{O}_{2}}(T$, $p^{0}$ ) is the chemical potential at $p^{0}$, which was obtained from thermodynamic tables. ${ }^{30}$

\section{RESULTS AND DISCUSSIONS}

Adsorption of Vanadia Clusters on $\mathrm{TiO}_{2}$. We start by investigating the structures of the adsorbed monomer, dimer, and tetramer vanadia clusters of different oxidation states. Specifically, we have examined the adsorption of $\mathrm{VO}_{1-4}$, $\mathrm{V}_{2} \mathrm{O}_{2-5}$, and $\mathrm{V}_{4} \mathrm{O}_{4-8}$ on both anatase $\mathrm{TiO}_{2}(001)$ and rutile $\mathrm{TiO}_{2}(110)$ supports. The most stable clusters are presented in Figure 1 (anatase $\mathrm{TiO}_{2}$ ) and Figure $2\left(\right.$ rutile $\mathrm{TiO}_{2}$ ); their

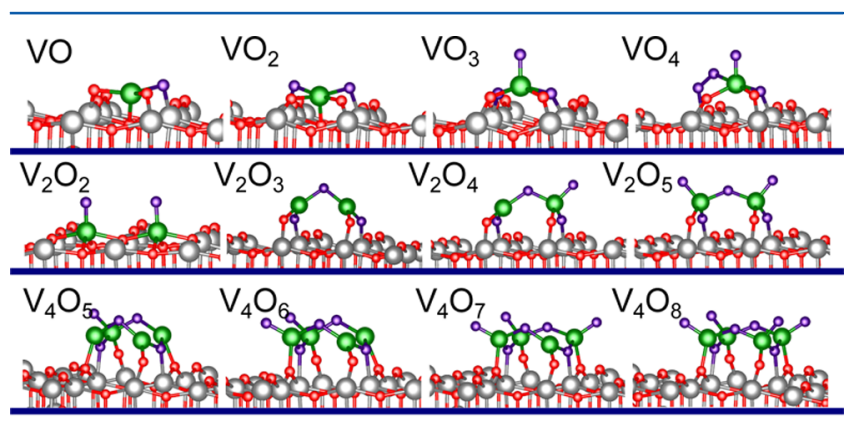

anatase $\mathrm{TiO}_{2}(001)$

Figure 1. Stable structures of $\mathrm{VO}_{1-4}, \mathrm{~V}_{2} \mathrm{O}_{2-5}$, and $\mathrm{V}_{4} \mathrm{O}_{4-8}$ supported on the anatase $\mathrm{TiO}_{2}(001)$ surface. In the figure, $\mathrm{Ti}$ and $\mathrm{V}$ atoms are represented by gray and green spheres, respectively; lattice $\mathrm{O}$ atoms originally from the substrate are red and $\mathrm{O}$ atoms from the environment are purple.

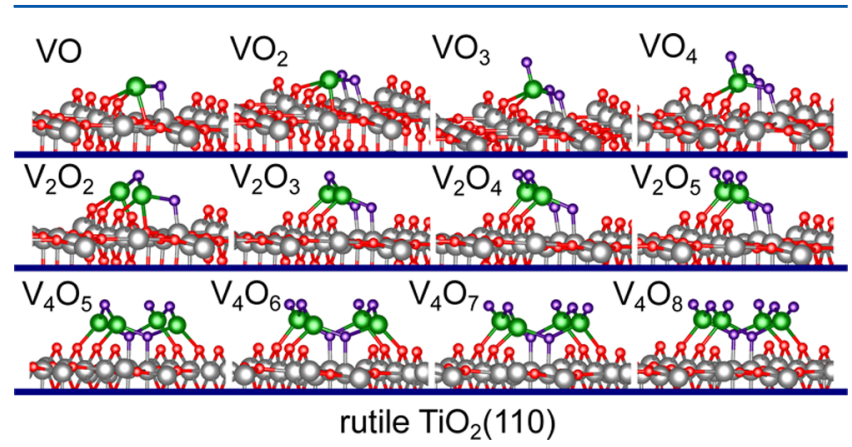

Figure 2. Stable structures of $\mathrm{VO}_{1-4}, \mathrm{~V}_{2} \mathrm{O}_{2-5}$, and $\mathrm{V}_{4} \mathrm{O}_{4-8}$ supported on the rutile $\mathrm{TiO}_{2}(001)$ surface. Atomic coloring is as in Figure 1.

corresponding formation energies and some structural values are summarized in Table 1. To understand the tendency for dispersion versus aggregation (i.e., the relative stability of each cluster size), the formation energy of each cluster is reported per $\mathrm{V}$ atom.
$V_{n} \mathrm{O}_{m}$ Cluster Adsorbed on Anatase $\mathrm{TiO}_{2}(001)$. The adsorption of $\mathrm{VO}$ on anatase $\mathrm{TiO}_{2}$ induces reconstruction of the $\mathrm{TiO}_{2}$ surface. Two $\mathrm{TiO}_{2}$ lattice oxygens are pulled out of the surface plane by the $\mathrm{V}$ atom to share bonding with the surface $\mathrm{Ti}$, generating two pseudo-oxygen-vacancies in the process. This bonding motif was found previously for $\mathrm{VO}$ adsorption on the $\mathrm{CeO}_{2}(111)$ surface. ${ }^{31}$ The $\mathrm{V}$ atom is coordinated with three $\mathrm{Ti}-\mathrm{O}-\mathrm{V}$ bridging oxygen species with an additional lattice oxygen from $\mathrm{TiO}_{2}$ directly beneath it. Upon VO adsorption, a surface $\mathrm{Ti}$ atom is reduced from 4+ to $3+$. The total magnetic moment of the $\mathrm{VO} / \mathrm{TiO}_{2}$ cluster is calculated to be $3 \mu_{\mathrm{B}}$ with one Bohr magneton on the reduced $\mathrm{Ti}$ atom, and the other two on the $\mathrm{V}$ atom. Hence, the oxidation state of $\mathrm{V}$ in the adsorbed $\mathrm{VO}$ cluster is $3+$, consistent with having three coordinating $\mathrm{O}$ atoms. In $\mathrm{VO}_{2}$, an additional $\mathrm{O}$ atom bridges the reduced $\mathrm{Ti}$ and $\mathrm{O}$ atoms, stabilizing the vanadia cluster by nearly $2 \mathrm{eV}$. Consequently, the $\mathrm{V}$ atom is further oxidized to 4+ and the reduced $\mathrm{Ti}$ atom recovers its 4+ bulk oxidation state. Upon further oxidation of $\mathrm{VO}_{2}$ to $\mathrm{VO}_{3}$, a vanadyl group $(\mathrm{V}=\mathrm{O})$ is formed. Different from a normal vanadyl group, in which the $\mathrm{V}$ atom provides two valence electrons to share with the terminal oxygen, the $\mathrm{V}$ atom in the adsorbed $\mathrm{VO}_{3}$ contributes only one electron to the $\mathrm{V}=\mathrm{O}$ double bond. The other electron in the $\mathrm{V}=\mathrm{O}$ bond is donated from the $\mathrm{TiO}_{2}$ support. A Bader charge density analysis on the adsorbed $\mathrm{VO}_{2}$ and $\mathrm{VO}_{3}$ cluster used to determine this charge transfer, as shown in Figure 3a. Upon formation of the vanadyl group, the adsorbed vanadia cluster gains a charge of $0.43 e$. It manifests that the double bond formation is not only due to the hybridization between the $\mathrm{V}$ and the $\mathrm{O}$ atoms but there is also a charge transfer from the substrate which contributes to the $\mathrm{V}=$ $\mathrm{O}$ double bond. Further analysis shows that the $\mathrm{V}$ atom has zero magnetic moment ( $5+$ valency) and a magnetic moment of $1 \mu_{\mathrm{B}}$ is associated with a surface $\mathrm{O}$ atom.

From $\mathrm{VO}_{2}$ to $\mathrm{VO}_{3}$, the formation energy decreases by 0.61 $\mathrm{eV}$. This relatively mild stabilization is due to the fact that only one electron is shared between the $\mathrm{V}$ atom and the additional $\mathrm{O}$ atom, so that the surface $\mathrm{Ti}-\mathrm{O}$ bond strength is reduced by the charge transfer. Since the $\mathrm{V}$ atom has already reached the valency saturation limit in the $\mathrm{VO}_{3}$ cluster, it cannot be further oxidized; no stable $\mathrm{VO}_{4}$ cluster was found.

Our calculated structures of the adsorbed vanadia monomer are different from what has been proposed as tetrahedrally coordinated $\mathrm{VO}_{4}$ (a different nomenclature is used here, counting all oxygen atoms bound to the $\mathrm{V}$ atom). This conclusion has been drawn from the previous work of Shapovalov, in which the vanadia monomer on the rutile $\mathrm{TiO}_{2}(110)$ surface was studied. ${ }^{16}$ The $\mathrm{V}$ atom in the monomer $\left(\mathrm{VO}_{3}\right)$ has a $5+$ oxidation state and a distorted octahedral coordination, which is the same as calculated here. We extend this conclusion to the anatase $\mathrm{TiO}_{2}(001)$ surface, where the $\mathrm{V}$ atom in the stable $\mathrm{VO}_{3}$ cluster also has a distorted octahedral coordination. This structure has been employed in a mechanistic study. ${ }^{32}$ For the same stoichiometry, a set of structures of the vanadia monomer has been calculated. The conventional tetrahedrally coordinated structure is found to be $0.85 \mathrm{eV}$ less stable than the global minimum. The so-called umbrella structure having two terminal oxygen atoms ${ }^{33}$ is less stable by $1.5 \mathrm{eV}$. On the other hand, in the vanadia dimer and tetramer clusters, the $\mathrm{VO}_{4}$ tetrahedral structures are stable.

The adsorption of the vanadia dimer cluster on anatase $\mathrm{TiO}_{2}$ is simpler than the monomer. The formation energies of adsorbed $\mathrm{V}_{2} \mathrm{O}_{\mathrm{m}}$ dimers systematically decreases by roughly the 
Table 1. Formation Energies of Vanadium Oxide Clusters As Well As Vanadyl Bond Lengths and Frequencies

\begin{tabular}{|c|c|c|c|c|c|c|}
\hline & \multicolumn{3}{|c|}{ anatase $\mathrm{TiO}_{2}(001)$} & \multicolumn{3}{|c|}{ rutile $\mathrm{TiO}_{2}(110)$} \\
\hline & $d_{\mathrm{V}=\mathrm{o}}(\AA)$ & $\nu_{\mathrm{V}=\mathrm{o}}\left(\mathrm{cm}^{-1}\right)$ & $E_{V n}^{\mathrm{f}} O_{m} / n_{\mathrm{V}}(\mathrm{eV})$ & $d_{\mathrm{V}=\mathrm{o}}(\AA)$ & $\nu_{\mathrm{V}=\mathrm{o}}\left(\mathrm{cm}^{-1}\right)$ & $E_{V n}^{\mathrm{f}} O_{m} / n_{\mathrm{V}}(\mathrm{eV})$ \\
\hline VO & & & -3.03 & & & -0.44 \\
\hline $\mathrm{VO}_{2}$ & & & -5.06 & & & -2.89 \\
\hline $\mathrm{VO}_{3}$ & 1.596 & 1024 & -5.67 & 1.598 & 1023 & -3.35 \\
\hline $\mathrm{VO}_{4}$ & 1.604 & 1006 & -5.61 & 1.597 & 1027 & -3.48 \\
\hline $\mathrm{V}_{2} \mathrm{O}_{2}$ & 1.631 & 962 & -1.42 & & & -0.57 \\
\hline $\mathrm{V}_{2} \mathrm{O}_{3}$ & & & -3.03 & & & -1.64 \\
\hline $\mathrm{V}_{2} \mathrm{O}_{4}$ & 1.611 & 1004 & -4.26 & 1.605 & 1017 & -2.82 \\
\hline $\mathrm{V}_{2} \mathrm{O}_{5}$ & 1.608 & 1010 & -5.35 & 1.603 & 1022 & -3.92 \\
\hline $\mathrm{V}_{4} \mathrm{O}_{5}$ & 1.618 & 988 & -1.60 & 1.637 & 950 & -1.23 \\
\hline $\mathrm{V}_{4} \mathrm{O}_{6}$ & $1.612 / 1.625$ & $1003 / 975$ & -2.23 & 1.622 & 977 & -1.74 \\
\hline $\mathrm{V}_{4} \mathrm{O}_{7}$ & $1.608 / 1.624$ & $1013 / 979$ & -2.81 & 1.620 & 983 & -2.29 \\
\hline $\mathrm{V}_{4} \mathrm{O}_{8}$ & $1.605 / 1.620$ & $1017 / 985$ & -3.39 & $1.599 / 1.617$ & $1031 / 988$ & -2.82 \\
\hline
\end{tabular}

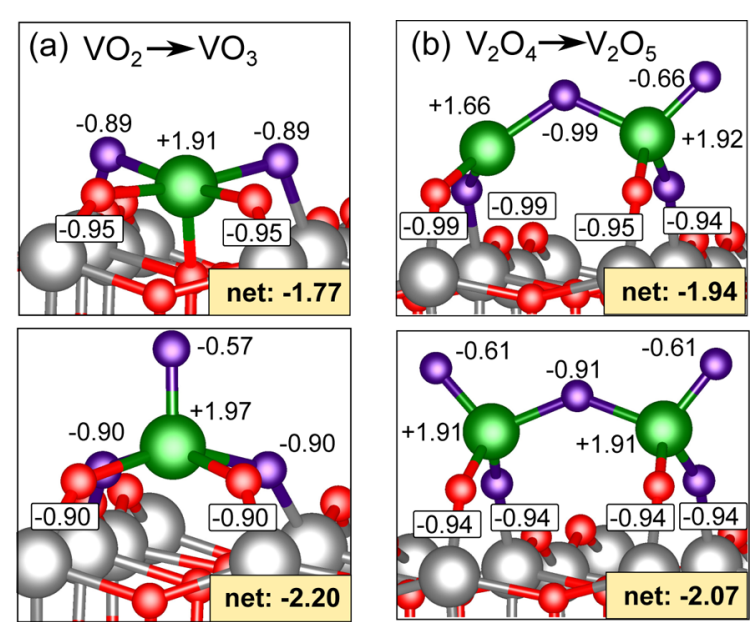

Figure 3. Bader charges on the adsorbed $\mathrm{V}_{n} \mathrm{O}_{m}$ clusters supported on anatase $\mathrm{TiO}_{2}$ support (a) $\mathrm{VO}_{2}$ and $\mathrm{VO}_{3}$ and rutile $\mathrm{TiO}_{2}$ support (b) $\mathrm{V}_{2} \mathrm{O}_{4}$ and $\mathrm{V}_{2} \mathrm{O}_{5}$.

same amount with the addition of each $\mathrm{O}$ atom. The most stable dimer cluster is $\mathrm{V}_{2} \mathrm{O}_{5}$, as expected because it has the same stoichiometry of the $\mathrm{V}_{2} \mathrm{O}_{5}$ bulk oxide. The $\mathrm{V}$ atoms in the adsorbed $\mathrm{V}_{2} \mathrm{O}_{5}$ cluster are coordinated with one $\mathrm{V}-\mathrm{O}-\mathrm{V}$ bridging $\mathrm{O}$, two $\mathrm{V}-\mathrm{O}-\mathrm{Ti}$ bridging $\mathrm{O}$, and one $\mathrm{O}$ atom in the vanadyl group. Consistent with bond-counting in this structure, the oxidation state of the $\mathrm{V}$ atoms is determined to be $5+$. Similar to the monomer, $\mathrm{V}_{2} \mathrm{O}_{5}$ adsorption causes two lattice oxygen atoms from $\mathrm{TiO}_{2}$ to form $\mathrm{V}-\mathrm{O}-\mathrm{Ti}$ bridging oxygens. The per- $\mathrm{V}$ formation energy of the adsorbed $\mathrm{V}_{2} \mathrm{O}_{5}$ is a little higher than that of the most stable $\mathrm{VO}_{3}$ monomer. The dimer has less charge transfer from the substrate $(0.1 e)$ as compared to the monomer $(0.4 e)$, as illustrated in Figure $3 \mathrm{~b}$. The monomer oxidation is primarily due to $\mathrm{V}-\mathrm{O}$ hybridization.

The most stable tetramer on the anatase $\mathrm{TiO}_{2}$ substrate is $\mathrm{V}_{4} \mathrm{O}_{8}$. Two types of $\mathrm{V}$ atoms exist in the $\mathrm{V}_{4} \mathrm{O}_{8}$ cluster. The first type of $\mathrm{V}$ atom is coordinated with two $\mathrm{V}-\mathrm{O}-\mathrm{V} \mathrm{O}$ atoms, one $\mathrm{V}-\mathrm{O}-\mathrm{Ti} \mathrm{O}$, and a vanadyl group. The oxidation state of this $\mathrm{V}$ atom is $5+$. The second type of $\mathrm{V}$ atom is also coordinated with two $\mathrm{V}-\mathrm{O}-\mathrm{V} \mathrm{O}$ atoms and one $\mathrm{O}$ in the vanadyl group; there is no $\mathrm{V}-\mathrm{O}-\mathrm{Ti} \mathrm{O}$ bound to this $\mathrm{V}$ atom. Instead, the $\mathrm{V}$ atom only weakly interacts with a $\mathrm{TiO}_{2}$ lattice oxygen bridging two $\mathrm{Ti}$ atoms. The $\mathrm{V}$ atom of the second type is $4+$. On the substrate, there are two reduced $\mathrm{Ti}$ atoms that bond with only one bridging oxygen. The other three tetramers have $\mathrm{V}^{3+}$ atoms with no vanadyl oxygen bonding.

With regard to the oxidation state of the $\mathrm{V}$ atom, in the vanadia monomer and dimer, $\mathrm{V}$ atoms can reach an oxidation state of $5+$ in the most oxidized form $\left(\mathrm{VO}_{3}\right.$ for the monomer, $\mathrm{V}_{2} \mathrm{O}_{5}$ for the dimer), whereas the vanadia tetramer $\left(\mathrm{V}_{4} \mathrm{O}_{8}\right)$ has mixed $\mathrm{V}^{5+}$ and $\mathrm{V}^{4+}$ oxidation states depending on the registry with the substrate. All $\mathrm{VO}_{3}, \mathrm{~V}_{2} \mathrm{O}_{5}$, and $\mathrm{V}_{4} \mathrm{O}_{8}$ have vanadyl groups. The vanadyl group in $\mathrm{VO}_{3}$ is stabilized by an electron transferred from the substrate to the double bond. In larger clusters, the vanadyl group forms due to the local hybridization between the $\mathrm{V}$ and $\mathrm{O}$ atoms. Interestingly, the vibrational frequency of the vanadyl bond varies systematically with the oxidation state of the V atoms. Summarizing, from Table 1, the vibrational frequency of the $\mathrm{V}=\mathrm{O}$, when $\mathrm{V}$ is $5+$, is in the range of $1000-1020 \mathrm{~cm}^{-1}$, while if the $\mathrm{V}$ atom is reduced to $4+$, the $\mathrm{V}=\mathrm{O}$ length is elongated and the vibrational frequency decreases to $980 \mathrm{~cm}^{-1}$.

$\mathrm{V}_{n} \mathrm{O}_{m}$ Cluster on Rutile $\mathrm{TiO}_{2}(110)$. The electronic structure of adsorbed vanadia clusters on rutile $\mathrm{TiO}_{2}(110)$ is similar to that on the anatase $\mathrm{TiO}_{2}(001)$ surface. Briefly, in the adsorbed vanadia monomer, the $\mathrm{V}$ atom in $\mathrm{VO}_{2}$ is $4+$, and it can be further oxidized to $5+$ in $\mathrm{VO}_{3}$. The support plays an active role in facilitating the formation of the vanadyl group through transferring one electron to the adsorbate. The most stable vanadia dimer is $\mathrm{V}_{2} \mathrm{O}_{5}$ in which the $\mathrm{V}$ atoms are $5+$. The $\mathrm{V}_{4} \mathrm{O}_{8}$ cluster on the rutile support is also reduced. Three out of the four $\mathrm{V}$ atoms in the $\mathrm{V}_{4} \mathrm{O}_{8}$ cluster have oxidation states of 4+, while the other is 5+. On the support, a Ti atom is reduced.

Despite the similarity in electronic structure, from these calculations, we conclude that the anatase and the rutile supports have a pronounced difference in how they stabilize vanadia oxide clusters. Specifically, there is a lower formation energy on the anatase substrate. The difference is expected to result in a different ability in dispersing vanadia clusters, which will be quantified using thermodynamical considerations in the next section. Structurally, the surface of the anatase support is significantly reconstructed upon vanadia cluster adsorption. The generation of pseudo-oxygen-vacancies on the anatase substrate manifest the reactive nature of the anatase $\mathrm{TiO}_{2}(001)$ surface. On the other hand, the structure of rutile $\mathrm{TiO}_{2}(110)$ surface is largely intact, indicating the passive nature of the surface.

Thermodynamic Stability of Vanadia Clusters. The ab initio thermodynamics method is used to examine the relative stability of the vanadia clusters in an oxygen environment, to 
find the most stable clusters for realistic catalytic conditions. Figure 4 shows the stability of the clusters on both the anatase and rutile substrates, as defined in eq 1, plotted as a function of the oxygen chemical potential, $\Delta \mu_{\mathrm{O}}$.
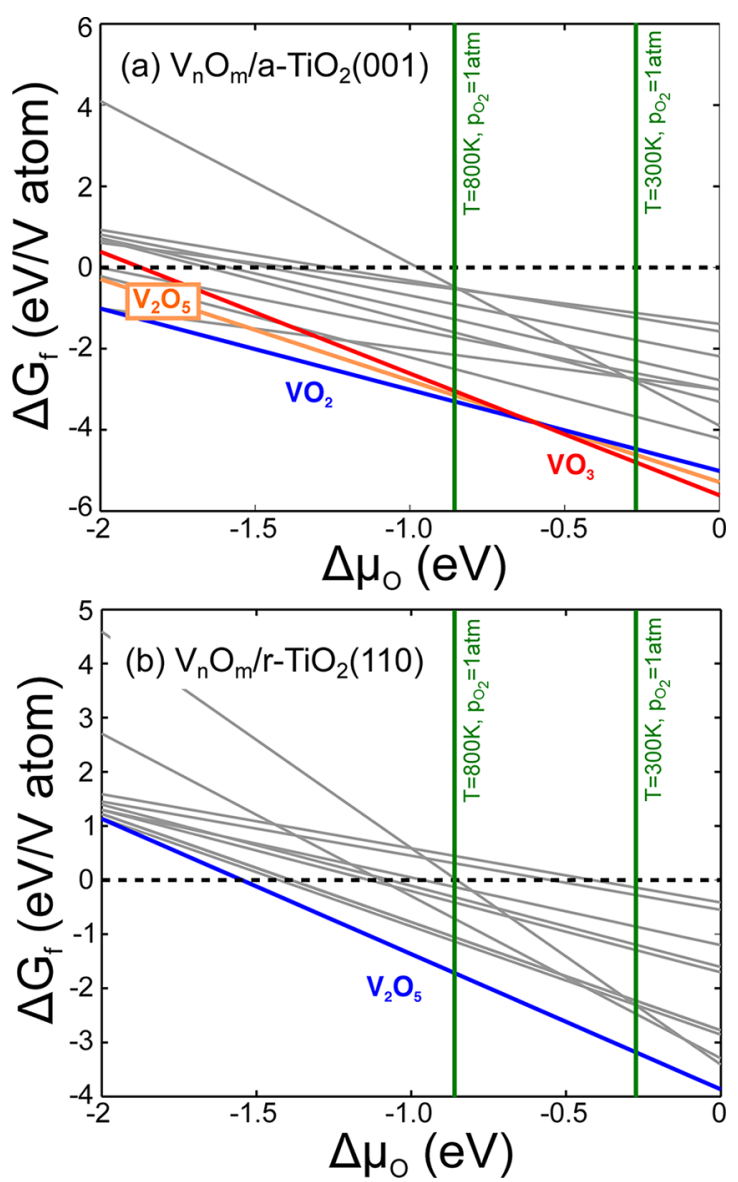

Figure 4. Free energy of formation of various $\mathrm{V}_{n} \mathrm{O}_{m}$ clusters adsorbed on the (a) anatase $\mathrm{TiO}_{2}(001)$ and (b) rutile $\mathrm{TiO}_{2}(110)$ surfaces as a function of oxygen chemical potential. Lines belong to the stable vanadia clusters are highlighted with colors while those unstable structures are presented with gray lines only. The oxygen chemical potential range corresponding to normal ODH reaction conditions $\left(p_{\mathrm{O}_{2}}=1 \mathrm{~atm}, T=300-800 \mathrm{~K}\right)$ are denoted with vertical lines.

On the anatase support, the $\mathrm{VO}_{2}$ and $\mathrm{VO}_{3}$ clusters are stable under low and high oxygen chemical potential, respectively, as Figure 4a shows. The crossover between these two clusters is in the oxygen chemical potential range of the relevant reaction conditions, which means that at these conditions the vanadia monomer can be reduced and reoxidized. The $\mathrm{V}_{2} \mathrm{O}_{5}$ cluster has a similar formation energy as compared to $\mathrm{VO}_{2}$ and $\mathrm{VO}_{3}$, so it is expected to have a considerable population on the substrate. Other clusters are less stable at higher oxygen chemical potentials due to their reduced nature.

On the rutile support, as shown Figure $4 b$, the $\mathrm{V}_{2} \mathrm{O}_{5}$ cluster is the most stable over the entire range of oxygen chemical potential considered. This finding agrees with a STM study of the vanadium oxide structures on $\mathrm{TiO}_{2}(110)$. It was found that depositing $0.2 \mathrm{ML}$ of V-oxide at $473 \mathrm{~K}$ in an $5 \times 10^{-8} \mathrm{mbar}_{2}$ environment results in a dimeric vanadia adsorbate. ${ }^{34} \mathrm{~A}$ recent experimental study confirmed that monomeric vanadia species are not stable but rather aggregate into polymeric species on $\mathrm{TiO}_{2}(110)$. Although the vanadia adsorbate in that study was resolved to be $\mathrm{V}_{4} \mathrm{O}_{6}$, the trend toward monomer aggregation is clear.

Structure-Reactivity Relationship. Hydrogen abstraction by a surface oxygen species has been identified as the ratedetermining step in the $\mathrm{ODH}$ reaction of propane and methanol. ${ }^{10,35,36}$ In both cases, the reaction energy can be decomposed into $\mathrm{C}-\mathrm{H}$ bond dissociation, which remains constant for different catalysts and the hydrogenation energy of surface oxygen species. The Brønsted-Evans-Polanyi (BEP) principle suggests a linear relationship between energy barriers and reaction energies for catalytic steps. The more exothermic the hydrogenation energy, the higher the activity of the catalyst. The hydrogenation energies have been calculated on the most stable monomer, dimer, and tetramer structure, as listed in Table 2. All possible surface oxygen sites on $\mathrm{VO}_{x}$ catalysts

Table 2. Hydrogenation Energies of $\mathrm{O}$ Species in $\mathrm{V}_{n} \mathrm{O}_{m}$ Clusters

\begin{tabular}{|c|c|c|c|}
\hline & \multicolumn{3}{|c|}{ hydrogenation energy $(\mathrm{eV})$} \\
\hline & anatase $\mathrm{TiO}_{2}(001)$ & & rutile $\mathrm{TiO}_{2}(110)$ \\
\hline & \multicolumn{3}{|c|}{$\mathrm{VO}_{3}$} \\
\hline $\mathrm{O} 1$ & -1.79 & & -2.17 \\
\hline $\mathrm{O} 2$ & -2.26 & & -2.49 \\
\hline $\mathrm{O} 3$ & -1.86 & & -2.29 \\
\hline $\mathrm{O} 4$ & -2.66 & & -2.02 \\
\hline \multirow[t]{2}{*}{ O5 } & - & & -2.51 \\
\hline & \multicolumn{3}{|c|}{$\mathrm{V}_{2} \mathrm{O}_{5}$} \\
\hline $\mathrm{O} 1$ & -0.70 & & -0.86 \\
\hline $\mathrm{O} 2$ & -0.20 & & -0.34 \\
\hline $\mathrm{O} 3$ & -0.26 & & -0.83 \\
\hline $\mathrm{O} 4$ & -0.16 & & +0.12 \\
\hline O5 & -1.16 & & -0.84 \\
\hline \multirow[t]{2}{*}{ O6 } & - & & -0.72 \\
\hline & \multicolumn{3}{|c|}{$\mathrm{V}_{4} \mathrm{O}_{8}$} \\
\hline $\mathrm{O} 1$ & -0.79 & & -0.91 \\
\hline $\mathrm{O} 2$ & -1.01 & & -0.81 \\
\hline $\mathrm{O} 3$ & -0.38 & & -0.16 \\
\hline $\mathrm{O} 4$ & +0.15 & & -0.32 \\
\hline O5 & -0.16 & & -0.86 \\
\hline O6 & +0.11 & & - \\
\hline O7 & -0.15 & & - \\
\hline \multirow[t]{2}{*}{ O8 } & -1.17 & & - \\
\hline & \multicolumn{3}{|c|}{$\mathrm{V}_{2} \mathrm{O}_{5}(001)$} \\
\hline $\mathrm{O} 1$ & -0.98 & & \\
\hline $\mathrm{O} 2$ & -0.86 & & \\
\hline $\mathrm{O} 3$ & -0.58 & & \\
\hline
\end{tabular}

supported on the anatase, rutile, and single crystal $\mathrm{V}_{2} \mathrm{O}_{5}(001)$ surface are considered and marked as shown in Figure 5 (panels a, b, and c, respectively).

For supported $\mathrm{VO}_{3}$ on the anatase $\mathrm{TiO}_{2}(001)$ surface, the most stable $\mathrm{H}$ adsorption occurs on a surface oxygen (O4) with a hydrogenation energy of $-2.66 \mathrm{eV} . \mathrm{H}$ adsorption on other oxygen sites, although less stable than that on the $\mathrm{O} 4$ site, are also significantly exothermic, ranging from -2.26 to $-1.79 \mathrm{eV}$. Upon hydrogenation of $\mathrm{VO}_{3}$, the $\mathrm{V}$ remains in the 5+ oxidation state because the electron from the hydrogen atom fills the electron hole formed due to charge transfer from the substrate to the vanadyl group. Hydrogenation of $\mathrm{VO}_{3}$ supported on rutile $\mathrm{TiO}_{2}(110)$ is similar. On the supported $\mathrm{V}_{2} \mathrm{O}_{5}$ cluster on rutile $\mathrm{TiO}_{2}(110)$, the most stable $\mathrm{H}$ adsorption occurs on the oxygen in the vanadyl group. On the anatase supported vanadia 


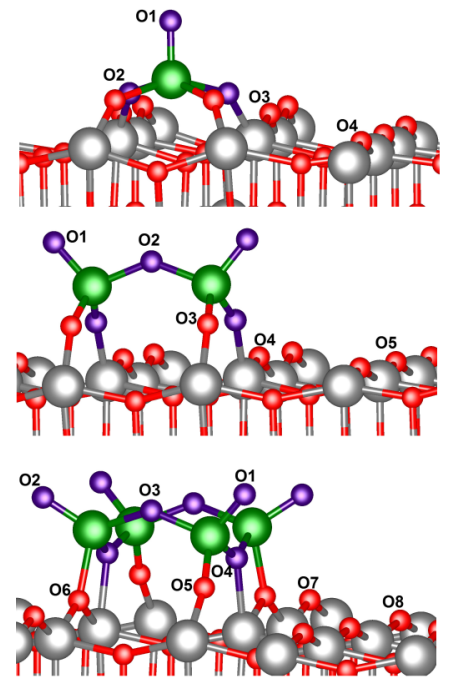

(a)
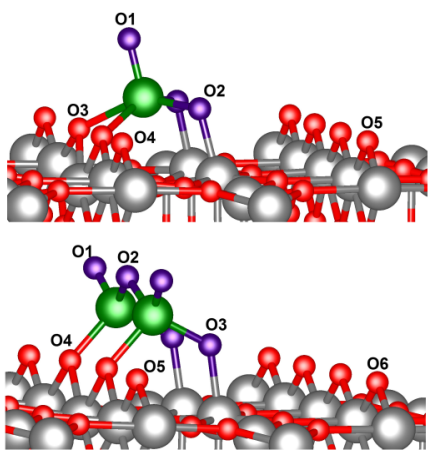

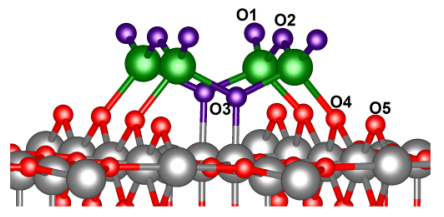

(b)

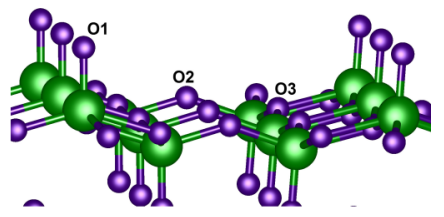

(c)

Figure 5. Oxygen species in $\mathrm{V}_{n} \mathrm{O}_{m}$ clusters adsorbed on (a) anatase $\mathrm{TiO}_{2}(001)$ and (b) rutile $\mathrm{TiO}_{2}(110)$ surfaces, as well as (c) the crystalline $\mathrm{V}_{2} \mathrm{O}_{5}(001)$ surface.
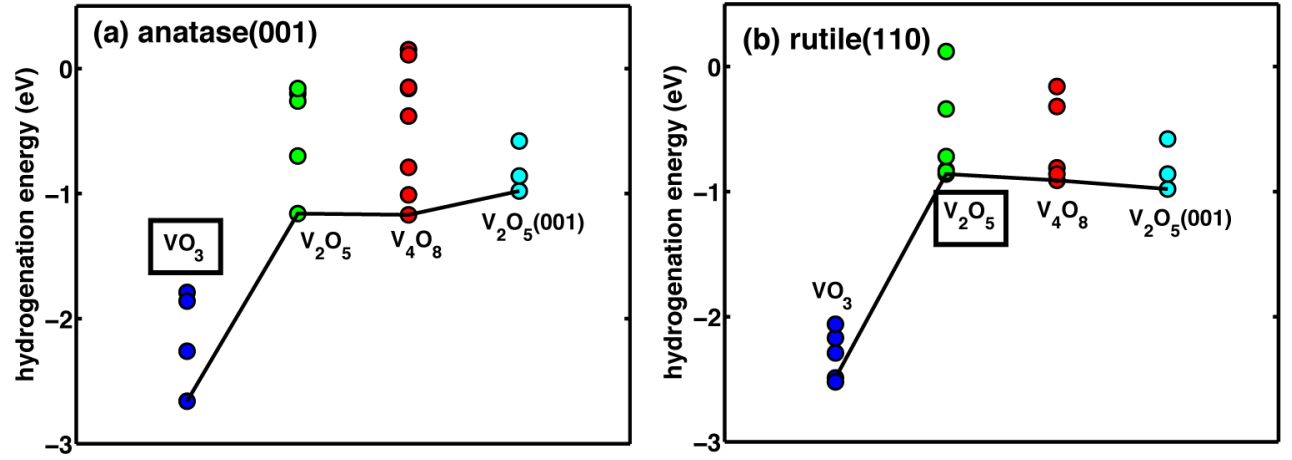

Figure 6. Hydrogenation energy trend for $\mathrm{V}_{n} \mathrm{O}_{m}$ clusters supported on $(\mathrm{a})$ anatase $\mathrm{TiO}_{2}(001)$ and (b) rutile $\mathrm{TiO}_{2}(110)$ surfaces with respect to cluster size; the crystalline $\mathrm{V}_{2} \mathrm{O}_{5}(001)$ surface is included for comparison.

dimer, the most stable $\mathrm{H}$ adsorption site is on a surface $\mathrm{O}$ atom. The associated hydrogenation energies are -1.16 and $-0.86 \mathrm{eV}$ on the anatase and rutile substrates, respectively. Upon $\mathrm{H}$ adsorption, the $\mathrm{V}$ atom in the vanadyl group is reduced to 4+ oxidation state. On the $\mathrm{V}_{4} \mathrm{O}_{8}$ cluster supported on anatase $\mathrm{TiO}_{2}$, hydrogen is most stable on a lattice oxygen of the $\mathrm{TiO}_{2}$ support with an adsorption energy of $-1.17 \mathrm{eV}$. The second most stable $\mathrm{H}$ adsorption occurs on an oxygen in the vanadyl group with an energy of $-1.01 \mathrm{eV}$, reducing the oxidation state of the vanadyl group from $4+$ to $3+$. This latter binding is favored on the rutile support, with an energy of $-0.91 \mathrm{eV}$.

$\mathrm{H}$ adsorption energies versus cluster size can be found from the data in Figure 6 (panels a and b) for anatase and rutile supports, respectively. Clearly, the $\mathrm{H}$ adsorption energy on monomeric vanadia is more exothermic than on larger clusters, where the binding is similar to the $\mathrm{V}_{2} \mathrm{O}_{5}(001)$ surface. The exceptional $\mathrm{H}$ adsorption ability of the monomer vanadia cluster is expected to facilitate $\mathrm{C}-\mathrm{H}$ bond activation which is considered the rate-determining step in $\mathrm{ODH}$ reaction. Since the vanadia monomer is only stable on anatase $\mathrm{TiO}_{2}(001)$, it should be a more active support than the rutile $\mathrm{TiO}_{2}(110)$ support.

Due to the large negative hydrogenation energy, the supported $\mathrm{VO}_{x}$ catalyst could stay in the reduced form under reducing conditions and subsequently induce structural transformations. In experiment, this structural transformation from a monomer in an oxidizing environment to a polymer in a reducing environment has been observed. ${ }^{14}$ In this study, we limit our discussions to the structure and activity of the fully oxidized $\mathrm{VO}_{x}$ catalyst. Understanding the stability and activity of reduced $\mathrm{V}_{n} \mathrm{O}_{m}$ clusters is a direction of future study.

\section{CONCLUSIONS}

DFT calculations have been performed to investigate the structure-activity relationship of supported vanadia cluster on anatase and rutile $\mathrm{TiO}_{2}$ substrates. We focus on the isolated vanadia monomer, dimer, and tetramer clusters, which are expected to be present in sub- $\mathrm{ML} \mathrm{VO}_{x} / \mathrm{TiO}_{2}$ catalysts. A search of possible structures of vanadia clusters has been conducted to find the most stable configurations. It was found, on both the anatase and rutile supports, that the $\mathrm{V}$ atom is octahedrally coordinated by $\mathrm{O}$ atoms in the vanadia monomer, whereas $\mathrm{V}$ atoms are tetrahedrally coordinated in the vanadia dimer and tetramer. An electron transfer from the substrate into the adsorbed $\mathrm{VO}_{3}$ cluster is found to play the role of stabilizing the vanadyl group. This charge transfer across substrate and adsorbate is only found in the monomeric vanadia cluster. In the adsorbed vanadia monomer and dimer, the $\mathrm{V}$ atom is 
pentavalent, while in the vanadia tetramer there is a mix of $\mathrm{V}^{4+}$ and $\mathrm{V}^{5+}$.

Examining the stability of these isolated vanadia clusters using $\mathrm{ab}$ initio thermodynamics suggests that the monomeric and dimeric vanadia clusters can coexist on the anatase $\mathrm{TiO}_{2}(001)$ surface in oxygen environments relevant to catalytic operating conditions. In contrast, the vanadia dimer is the stable adsorbate on the rutile $\mathrm{TiO}_{2}(110)$ surface. The difference of stable adsorbates on the two surfaces manifests the different ability in dispersing vanadia clusters. The anatase $\mathrm{TiO}_{2}(001)$ surface is more reactive and tends to bind smaller vanadia clusters to maximize the substrate-adsorbate interaction. The activity of the supported vanadia clusters are studied using $\mathrm{H}$ adsorption energy on the oxygen species as a descriptor. It is found that the monomeric vanadia cluster has a strong $\mathrm{H}$ adsorption energy of $-2.0 \mathrm{eV}$ due to charge transfer with the substrate. On larger vanadia clusters, the $\mathrm{H}$ adsorption energy is similar as on a single crystal $\mathrm{V}_{2} \mathrm{O}_{5}(001)$ surface. As a result, the enhanced performance of anatase toward the $\mathrm{ODH}$ reaction can be explained by the stabilized vanadia monomer cluster on the support.

\section{ASSOCIATED CONTENT}

\section{S Supporting Information}

Structures and corresponding formation energies for the metastable $\mathrm{V}_{n} \mathrm{O}_{m}$ clusters supported on the anatase $\mathrm{TiO}_{2}(001)$ and rutile $\mathrm{TiO}_{2}(110)$ surfaces. The Supporting Information is available free of charge on the ACS Publications website at DOI: 10.1021 acs.jpcc.5b02486.

\section{AUTHOR INFORMATION}

\section{Corresponding Authors}

*E-mail: fuhui@upc.edu.cn. Tel: +86 (0532) 8698-4559.

*E-mail: zhiyao.duan@cm.utexas.edu. Tel: +1 (412) 425-0174.

Notes

The authors declare no competing financial interest.

\section{ACKNOWLEDGMENTS}

This project is supported by the National Natural Science Foundation of China (Grant 21203250), China Scholarship Council, the Department of Energy under contract DE-FG0213ER16428, and the Welch Foundation under Grant F-1841. The calculations were done at the National Energy Research Scientific Computing Center and the Texas Advanced Computing Center.

\section{REFERENCES}

(1) Wachs, I. E. Recent Conceptual Advances in the Catalysis Science of Mixed Metal Oxide Catalytic Materials. Catal. Today 2005, 100, 79-94.

(2) Rodriguez, J. A.; Stacchiola, D. Catalysis and the Nature of Mixed-Metal Oxides at the Nanometer Level: Special Properties of $\mathrm{MO}_{x} / \mathrm{TiO}_{2}(110)\{\mathrm{M}=\mathrm{V}, \mathrm{W}, \mathrm{Ce}\}$ Surfaces. Phys. Chem. Chem. Phys. 2010, 12, 9557-9565.

(3) Stacchiola, D. J.; Senanayake, S. D.; Liu, P.; Rodriguez, J. A. Fundamental Studies of Well-Defined Surfaces of Mixed-Metal Oxides: Special Properties of $\mathrm{MO}_{\mathrm{x}} / \mathrm{TiO}_{2}(110)\{\mathrm{M}=\mathrm{V}, \mathrm{Ru}, \mathrm{Ce}$, or W\}. Chem. Rev. 2013, 113, 4373-4390.

(4) Wachs, I. E.; Weckhuysen, B. M. Structure and Reactivity of Surface Vanadium Oxide Species on Oxide Supports. Appl. Catal., A 1997, 157, 67-90.

(5) Wachs, I. E. Catalysis Science of Supported Vanadium Oxide Catalysts. Dalton Trans. 2013, 42, 11762-11769.
(6) Carrero, C. A.; Schloegl, R.; Wachs, I. E.; Schomaecker, R. Critical Literature Review of the Kinetics for the Oxidative Dehydrogenation of Propane over Well-Defined Supported Vanadium Oxide Catalysts. ACS Catal. 2014, 4, 3357-3380.

(7) Carrero, C. A.; Keturakis, C. J.; Orrego, A.; Schomäcker, R.; Wachs, I. E. Anomalous Reactivity of Supported $\mathrm{V}_{2} \mathrm{O}_{5}$ Nanoparticles for Propane Oxidative Dehydrogenation: Influence of the Vanadium Oxide Precursor. Dalton Trans. 2013, 42, 12644-12653.

(8) Artiglia, L.; Agnoli, S.; Savio, L.; Pal, J.; Celasco, E.; Rocca, M.; Bondino, F.; Magnano, E.; Castellarin-Cudia, C.; Netzer, F. P.; et al. From Vanadia Nanoclusters to Ultrathin Films on $\mathrm{TiO}_{2}(110)$ : Evolution of the Yield and Selectivity in the Ethanol Oxidation Reaction. ACS Catal. 2014, 3715-3723.

(9) Baron, M.; Abbott, H.; Bondarchuk, O.; Stacchiola, D.; Uhl, A.; Shaikhutdinov, S.; Freund, H.-J.; Popa, C.; Ganduglia-Pirovano, M.; Sauer, J. Resolving the Atomic Structure of Vanadia Monolayer Catalysts: Monomers, Trimers, and Oligomers on Ceria. Angew. Chem., Int. Ed. 2009, 48, 8006-8009.

(10) Ganduglia-Pirovano, M. V.; Popa, C.; Sauer, J.; Abbott, H.; Uhl, A.; Baron, M.; Stacchiola, D.; Bondarchuk, O.; Shaikhutdinov, S.; Freund, H.-J. Role of Ceria in Oxidative Dehydrogenation on Supported Vanadia Catalysts. J. Am. Chem. Soc. 2010, 132, 23452349.

(11) Price, S. P.; Tong, X.; Ridge, C.; Shapovalov, V.; Hu, Z.; Kemper, P.; Metiu, H.; Bowers, M. T.; Buratto, S. K. STM Characterization of Size-selected $\mathrm{V}_{1}, \mathrm{~V}_{2}, \mathrm{VO}$, and $\mathrm{VO}_{2}$ Clusters on a $\mathrm{TiO}_{2}(110)-(1 \times 1)$ Surface at Room Temperature. Surf. Sci. 2011, 605, 972-976.

(12) Artiglia, L.; Agnoli, S.; Vittadini, A.; Verdini, A.; Cossaro, A.; Floreano, L.; Granozzi, G. Atomic Structure and Special Reactivity Toward Methanol Oxidation of Vanadia Nanoclusters on $\mathrm{TiO}_{2}(110)$. J. Am. Chem. Soc. 2013, 135, 17331-17338.

(13) Feng, Z.; Cheng, L.; Kim, C.-Y.; Elam, J. W.; Zhang, Z.; Curtiss, L. A.; Zapol, P.; Bedzyk, M. J. Atomic-Scale Study of Ambient-Pressure Redox-Induced Changes for an Oxide-Supported Submonolayer Catalyst: $\mathrm{VO}_{\mathrm{x}} / \alpha-\mathrm{TiO}_{2}(110)$. J. Phys. Chem. Lett. 2012, 3, 2845-2850.

(14) Feng, Z.; Lu, J.; Feng, H.; Stair, P. C.; Elam, J. W.; Bedzyk, M. J. Catalysts Transform While Molecules React: An Atomic-Scale View. J. Phys. Chem. Lett. 2013, 4, 285-291.

(15) Kim, C.-Y.; Elam, J. W.; Stair, P. C.; Bedzyk, M. J. Redox Driven Crystalline Coherent-Incoherent Transformation for a $2 \mathrm{ML} \mathrm{VO}_{\mathrm{x}}$ Film Grown on $\alpha-\mathrm{TiO}_{2}(110)$. J. Phys. Chem. C 2010, 114, 19723-19726.

(16) Shapovalov, V.; Metiu, H. $\mathrm{VO}_{\mathrm{x}}(\mathrm{x}=1-4)$ Submonolayers Supported on Rutile $\mathrm{TiO}_{2}(110)$ and $\mathrm{CeO}_{2}(111)$ Surfaces: The Structure, the Charge of the Atoms, the XPS Spectrum, and the Equilibrium Composition in the Presence of Oxygen. J. Phys. Chem. C 2007, 111, 14179-14188.

(17) Kresse, G.; Hafner, J. Ab-initio Molecular Dynamics for Liquid Metals. Phys. Rev. B 1993, 47, 558.

(18) Kresse, G.; Furthmüller, J. Efficiency of Ab-initio Total Energy Calculations for Metals and Semiconductors Using a Plane-wave Basis Set. Comput. Mater. Sci. 1996, 6, 15-50.

(19) Kresse, G.; Furthmüller, J. Efficient Iterative Schemes for Abinitio Total-energy Calculations Using a Plane-wave Basis Set. Phys. Rev. B 1996, 54, 11169.

(20) Perdew, J. P.; Burke, K.; Ernzerhof, M. Generalized Gradient Approximation Made Simple. Phys. Rev. Lett. 1996, 77, 3865-3868.

(21) Blöchl, P. E. Projector Augmented-wave Method. Phys. Rev. B 1994, 50, 17953.

(22) Kresse, G.; Joubert, D. From Ultrasoft Pseudopotentials to the Projector Augmented-wave Method. Phys. Rev. B 1999, 59, 17581775.

(23) Dudarev, S. L.; Botton, G. A.; Savrasov, S. Y.; Humphreys, C. J.; Sutton, A. P. Electron-energy-loss Spectra and the Structural Stability of Nickel Oxide: An LSDA+U Study. Phys. Rev. B 1998, 57, 15051509.

(24) Morgan, B. J.; Watson, G. W. A.; DFT, U. Description of Oxygen Vacancies at the $\mathrm{TiO}_{2}$ Rutile (110) Surface. Surf. Sci. 2007, 601, 5034-5041. 
(25) Finazzi, E.; di Valentin, C.; Pacchioni, G.; Selloni, A. Excess Electron States in Reduced Bulk Anatase $\mathrm{TiO}_{2}$ : Comparison of Standard GGA, GGA+U, and Hybrid DFT Calculations. J. Chem. Phys. 2008, 129, 154113.

(26) Scanlon, D. O.; Walsh, A.; Morgan, B. J.; Watson, G. W. An abinitio Study of Reduction of $\mathrm{V}_{2} \mathrm{O}_{5}$ through the Formation of Oxygen Vacancies and Li Intercalation. J. Phys. Chem. C 2008, 112, 99039911.

(27) Henkelman, G.; Arnaldsson, A.; Jónsson, H. A Fast and Robust Algorithm for Bader Decomposition of Charge Density. Comput. Mater. Sci. 2006, 36, 354-360.

(28) Tang, W.; Sanville, E.; Henkelman, G. A Grid-Based Bader Analysis Algorithm Without Lattice Bias. J. Phys.: Condens. Matter 2009, 21, 084204.

(29) Reuter, K.; Scheffler, M. Composition, Structure, and Stability of $\mathrm{RuO}_{2}$ tpar110) as a Function of Oxygen Pressure. Phys. Rev. B 2001, $65,035406$.

(30) Chase, M. W., Davis, C. A., Downey, J. R., Frurip, D. J., McDonald, R. A., Syverud, A. N. JANAF Thermochemical Tables, 3rd ed J. Phys. Chem. Ref. Data. 1985, 14.

(31) Paier, J.; Kropp, T.; Penschke, C.; Sauer, J. Stability and Migration Barriers of Small Vanadium Oxide Clusters on the $\mathrm{CeO}_{2}(111)$ Surface Studied by Density Functional Theory. Faraday Discuss. 2013, 162, 233-245.

(32) Du, Y.-J.; Li, Z. H.; Fan, K.-N. A Theoretical Investigation on the Influence of Anatase Support and Vanadia Dispersion on the Oxidative Dehydrogenation of Propane to Propene. J. Mol. Catal. A: Chem. 2013, 379, 122-138.

(33) Gryboś, R.; Witko, M. Influence of Anatase Support on Geometrical Structure of Vanadium Oxide at Varying Temperatures and Pressures. Periodic DFT Study. J. Phys. Chem. C 2007, 111, 42164225.

(34) Agnoli, S.; Sambi, M.; Granozzi, G.; Castellarin-Cudia, C.; Surnev, S.; Ramsey, M. G.; Netzer, F. P. The Growth of Ultrathin Films of Vanadium Oxide on $\mathrm{TiO}_{2}(110)$. Surf. Sci. 2004, 562, 150156.

(35) Rozanska, X.; Fortrie, R.; Sauer, J. Oxidative Dehydrogenation of Propane by Monomeric Vanadium Oxide Sites on Silica Support. J. Phys. Chem. C 2007, 111, 6041-6050.

(36) Döbler, J.; Pritzsche, M.; Sauer, J. Oxidation of Methanol to Formaldehyde on Supported Vanadium Oxide Catalysts Compared to Gas Phase Molecules. J. Am. Chem. Soc. 2005, 127, 10861-10868. 